\title{
Research Report on Inventory Management of the Reserve Grain Management Corporation
}

\author{
Jianjun Zou \\ Guangdong Polytechnic of Industry and Commerce, Guangzhou, China \\ Email: 15989056266@163.com
}

How to cite this paper: Zou, J.J. (2019) Research Report on Inventory Management of the Reserve Grain Management Corporation. Modern Economy, 10, 844-852. https://doi.org/10.4236/me.2019.103056

Received: January 28, 2019

Accepted: March 19, 2019

Published: March 22, 2019

Copyright $\odot 2019$ by author(s) and Scientific Research Publishing Inc. This work is licensed under the Creative Commons Attribution International License (CC BY 4.0).

http://creativecommons.org/licenses/by/4.0/

\begin{abstract}
In the new situation of market economy, the competition of enterprises will become more and more intense. The management of inventory plays a vital role in how enterprises should survive and develop. Under normal circumstances, the management of enterprises will be unavoidable to exist in the problem of inventory management. On the contrary, when the stock is scarce, the market demand will be large, which will not be beneficial for the enterprises to increase sales revenue. Therefore, only the enterprise uses the method of inventory management, the enterprise can develop forward. According to the nature of enterprises, combining the characteristics of enterprises and strengthening the necessity of inventory management, this paper analyzes the current situation and causes of inventory management in Chinese enterprises, and is committed to propose corresponding countermeasures. This will collect data on inventory management, inventory management, taking A company as the research object, collect relevant theories of inventory management through the consult books, literature and network etc., realize the importance of inventory management of actual operation of enterprises, current situation of inventory management in A company, find the problems and put forward the corresponding solutions, hope to A after the company on the stock business and improve inventory management for reference, so as to promote the healthy development of enterprises.
\end{abstract}

\section{Keywords}

Enterprises, Inventory Management, Problems and Decisions

\section{Overview of the Reserve Grain Management Corporation}

\subsection{Introduction to the Reserve Grain Management Corporation}

The Grain Reserve Management Corporation is a large-scale central enterprise 
affiliated to the vertical management of China Grain Reserve Management Corporation. It is mainly responsible for the preservation and processing of central reserve grain and oil. The company has a warehouse area of 220,000 square kilometers and a total storage capacity of 368,000 tons, fixed assets of 110 million Yuan and current assets of 320 million Yuan. The company has 18 flat warehouses and 4 large shallow round warehouses. At present, it stores 630,000 tons of various policy foods [1].

\subsection{Current Status of Inventory of the Reserve Grain Management Corporation}

1) Inventory category

As can be seen from Table 1, the main grain varieties of the Reserve Grain Management Corporation are rice, oil and wheat. Its packaging method, storage method, inventory nature, etc. are all full of direct library characteristics [2].

2) Collection, distribution and storage of grain and oil stocks

The author through the official website of the Reserve Grain Management Corporation to inquire about the company's warehouse statement in 2016, and obtain the company's 2016 reserve grain and oil collection, distribution and storage, as shown in Table 2.

Table 1. Categories of grain and oil stocks.

\begin{tabular}{cl}
\hline Classification standard & \multicolumn{1}{c}{ Category } \\
\hline Grain varieties & Rice, oil and wheat, etc. \\
Packing method & Bulk class and packaging class \\
Storage methods & $\begin{array}{l}\text { Central reserve grain, local grain reserves, and entrusted storage } \\
\text { grain }\end{array}$ \\
Differentiated locations & $\begin{array}{l}\text { Small storage points, medium storage organizations, large storage } \\
\text { enterprises } \\
\text { Nature of inventory }\end{array}$ \\
& Commodity grain and oil, reserve grain and oil, rotation of grain \\
& and oil
\end{tabular}

Table 2. 2016 Reserves of grains and oils collection, Distribution and Stocks Unit: kg.

\begin{tabular}{|c|c|c|c|c|}
\hline Stock type & Initial stock & Instalment income & $\begin{array}{l}\text { Issued in the } \\
\text { current period }\end{array}$ & Ending stock \\
\hline $\begin{array}{c}\text { Central Reserve Grain } \\
\text { and Oil }\end{array}$ & $117,340,000.00$ & $56,651,000.00$ & $2,110,000.00$ & $172,972,000.00$ \\
\hline $\begin{array}{l}\text { Central temporary } \\
\text { reserve grain and oil }\end{array}$ & $8,380,340.00$ & 0.00 & 0.00 & $8,270,440.00$ \\
\hline $\begin{array}{l}\text { Minimum purchase } \\
\text { price of grain }\end{array}$ & $75,566,971.00$ & $142,478,404.00$ & $32,275,814.50$ & $185,693,548.50$ \\
\hline $\begin{array}{c}\text { Local reserve grain } \\
\text { and oil }\end{array}$ & 0.00 & $10,006,000.00$ & 0.00 & $10,015,000.00$ \\
\hline $\begin{array}{c}\text { Total reserves of grain } \\
\text { and oil }\end{array}$ & $202,281,011.00$ & $209,135,404.00$ & $34,365,814.50$ & $376,950,988.50$ \\
\hline
\end{tabular}

Source: Reserve Grain Management Corporation 2016 Warehouse Report. 
As can be seen from Table 2, the company's reserve grain and oil storage is huge each year. For inventory management, the most difficult is to save. Therefore, how to improve the company's inventory management status and improve the company's overall efficiency is the research focus of this paper.

\section{Current Status of Inventory Management of the Reserve Grain Management Corporation}

\subsection{Inventory Management Lacks Scientific and Reasonable Plans}

The inventory management of the Reserve Grain Management Corporation lacks a plan to control the procurement and storage of the enterprise's inventory, indicating that the internal control of the enterprise is not perfect. The company's inventory management model still uses the traditional inventory management model, and has not kept pace with the times. In the production and operation of enterprises, enterprises divide the inventory into common and not commonly used, and do not scientifically and reasonably divide the inventory. In the procurement process, when you really need to purchase, you only need to apply orally with the leader. There is no budget plan for the purchase amount. Generally, "Han Xin's soldiers, more and better" are easy to waste resources, and it is not conducive to building a resource-saving and environment-friendly society [3]. When the procurement department conducts enterprise procurement, it has too little communication with other departments of the company, such as warehouse personnel and sales personnel. As a result, the procurement situation may be out of line with reality, and the specific situation is not analyzed. In the warehousing of enterprises, companies generally put the most commonly used stocks in more conspicuous places, and put them in places such as corners. Since the company's inventory quantity and type are very large, and there is no information software to record the inventory information, the general classification and common use are based on the experience of inventory managers. More importantly, the commonly used, infrequently used inventory is only for a period of time or an order, which results in a very confusing inventory and lack of organization. Inventory management lacks institutional constraints and has no strict basis for division, which is not conducive to the long-term management of enterprise inventory management.

\subsection{Problems in the Inventory Management Procurement Process}

Purchasing is the basic environment for production and operation of enterprises. Inventory management in the procurement chain plays an important role in the whole inventory management. After analysis and investigation, it is found that the inventory management of the Reserve Grain Management Corporation has the following problems in the procurement process: First, the procurement procedures are complicated. The company has developed on the basis of stateowned enterprises and has paid great attention to the approval process. The preparation time for inventory procurement is relatively long, the approval is 
complicated, and there are many procedures. In this case, the company will consume a lot of manpower, material resources and financial resources in an unnecessary environment, taking up a long time of capital, which is not conducive to the rational and effective use of funds. In addition, because the supplier's time is not certain, the entire procurement process takes too long. Second, procurement leadership is scattered. The company does not stipulate management personnel who are responsible for the purchase of enterprise inventory, which leads to the management plan of each management leader, which is not conducive to the overall planning of the enterprise. There may be inconsistencies in the management leadership, which will lead to subordinates being overwhelmed and prone to conflicts. Third, there is no scientific and reasonable performance evaluation system. When measuring whether an employee completes a procurement task, the company simply pays attention to whether the employee completes the planned quantity and amount, and does not pay attention to the quality of the purchased inventory and the impact of the cost on the finished product [4].

\subsection{There Are Problems in Inventory Management and Storage}

Inventory management warehousing is also a very important part, involving storage costs, accidental losses and opportunity costs. After analysis, it is found that the Reserve Grain Management Corporation has the following problems in the warehousing environment: First, the inventory quality is not effectively guaranteed. The company's inventory procurement and warehousing personnel are the same person, which is highly prone to fraudulent practices and reports that the quality of the inventory is unqualified. If the quality of the inventory is not enough, it will cause hidden dangers for future production and operation [5]. The company is a grain storage enterprise, and product failure may cause food safety problems and even pose a threat to human life. Under this circumstance, enterprises have not placed the inspection of inventory qualifications in a prominent position, and simply pursuing price guidance is very unfavorable to the long-term operation of enterprises. Inventory procurement should not only focus on internal quality but also on external quality. Only when the quality is closed in the primary stage can we create reliable products. Second, there is no information system in the warehouse, and manual records are still used. In the face of the large inventory types and quantities, manual records simply cannot meet the demand, and it is easy to produce manual errors, which reduces the effectiveness of the warehousing data provided. Third, there is a lack of supervision in corporate inventory. The inventory data provided by the warehousing personnel is not supervised by other personnel, and only one person is responsible for the inventory data, resulting in a decrease in the significance of the inventory. Inventory without supervision is also prone to inventory losses. Warehousing personnel may not report the lost inventory, which is not conducive to the decision analysis of the management [6]. 


\subsection{Informatization of Inventory Management Is Low}

The trend of history is always the trend of the times. As China's informatization level continues to increase, the corresponding requirements for the degree of informationization of enterprises are also constantly increasing. However, the degree of informatization of Jiangxi Kaiyuan Company is relatively low, which leads to serious problems in information communication. There are two main problems in the informatization of the enterprise. On the one hand, the lack of modern application software for enterprises makes it difficult for enterprises to sort out the huge data. Moreover, there is only one person in the company's inventory management information, which cannot meet the needs of all aspects of the enterprise for inventory inspection. On the other hand, there are serious communication barriers between departments of the company such as finance department, purchasing department, sales department, etc [7]. Each department has its own information system, but only the personnel of this department have the right to enter, the work of other departments. People do not have permission to view data from other departments and cannot share resources. If you only rely on the delivery of paper documents, there is no doubt that its efficiency is very slow, and it is not conducive to the division of labor in various departments of the enterprise. No department of an enterprise exists independently. Only when various departments cooperate with each other can we make more reasonable and perfect inventory management decisions.

\section{Analysis of the Reasons for the Problems in Inventory Management of the Reserve Grain Management Corporation}

\subsection{The Lack of Professional Talents in Inventory Management}

The lack of talents related to inventory management of the Reserve Grain Management Corporation is mainly reflected in three aspects: First, the Grain Reserve Management Corporation is a company that has gradually developed from state-owned enterprises. Most of the company's veteran leaders have experienced the planned economy era, and this Thoughts are deeply rooted. Although the introduction of Western advanced inventory management mode at the beginning stage, it is only a slap in the face, and there is no real implementation of a new inventory management model in combination with the specific circumstances of the enterprise [8].

The times are progressing, and corporate management should also keep pace with the times. Most of the management leaders in the past thought that production was greater than the day, and as long as it was produced, it would be guaranteed. Second: Most employees or leaders of the company believe that inventory management is only the responsibility of the warehousing department. In fact, the concept of management and storage is different. Inventory management is more focused on management, requiring relevant personnel to have management expertise rather than simply In order to store management, how to better 
use management ideas for inventory management requires relevant professionals to develop effective plans to implement; Third: lack of management professional or management talents, manufacturing enterprises The promotion is relatively more focused on the accumulation of practical experience, and most of the current leadership is step by step in the company. However, it is undeniable that the management in this case is relatively lacking the opportunity to systematically accept management knowledge, lacking the awareness of inventory management from a macro perspective, and thus leading to the lack of effective protection of professional personnel in inventory management.

\subsection{The Internal Control System Is Not Sound}

The internal control system refers to a series of measures taken by enterprises in order to achieve production and operation objectives in the production and operation of enterprises. Perfect internal control can effectively strengthen the cooperation between various departments of the enterprise, and can fulfill the responsibility to the department and play the role of mutual restraint of various departments. With the development of social economy, enterprises are paying more and more attention to the effectiveness of internal control. Internal control runs through all aspects of production and management. How to better play the role of internal control is a very important system engineering and an important means to enhance the competitiveness of enterprises. The inventory management and warehousing personnel of the Reserve Grain Management Corporation are the same person, and the lack of supervision of inventory inventory indicates that their internal control system is not perfect, which increases the possibility of malpractice [9].

\section{Inventory Management Optimization Strategy of the Reserve Grain Management Corporation}

\subsection{Cultivating Professional Talents for Inventory Management}

Since the 18th National Congress, General Secretary Xi Jinping has emphasized the importance of talents at different conferences on different occasions. China has always implemented a strategy of strengthening the country through talents. Inventory management must also impose high standards and strict requirements on personnel training. Inventory management requires relatively high talents. It not only requires employees to have professional knowledge in accounting, but also requires employees to have systematic and comprehensive management training. However, the current staffing is obviously not in compliance with the requirements, and the accounting expertise is sufficient, but the lack of management knowledge is a weakness [10].

The company should have a good learning atmosphere, provide training opportunities for inventory management practitioners, and update their traditional knowledge structure. Actively use, for example, inviting experts in green accounting to provide free training for companies that disclose green accounting 
information, providing a good platform for these companies.

\subsection{Strengthening the Construction of Enterprise Information}

From the above discussion, it can be concluded that due to the low degree of informatization of the Grain Reserve Management Corporation, the communication between various departments of the enterprise is not smooth, which is not conducive to the long-term production and operation of the enterprise, and is not conducive to the rational and effective use of resources. Therefore, it is imperative to promote the development of informationization in enterprises. To strengthen the construction of enterprise information, we should first attach importance to and implement computerized management, which is the basic work. Enterprises should analyze the specific situation, start from their own production and operation, select the appropriate financial software, and establish a computerized inventory management system. Equipped with professional computerized management personnel to monitor the purchase, storage and sales of inventory in real time, providing real and effective data basis for enterprise decision makers [11].

More importantly, enterprises should enter inventory information into computers and gradually realize paperless office. In the long run, not only saves office costs but also improves the authenticity of inventory data. Second, companies should also pay attention to the electronic management of suppliers. The electronic management of suppliers is to achieve information sharing with suppliers, reduce procurement costs, reduce storage costs and improve the economic efficiency of enterprises.

\subsection{Improve the Internal Control System}

A sound internal control system can reduce the operating costs of enterprises and reduce the possibility of malpractice. First, the inventory business responsibility system should be established. Different positions have different responsibilities, which can effectively divide the scope of responsibility and ensure the separation and supervision of incompatible positions. Second, strengthen the authorization and approval management. Authorization and approval must be reflected in the words, oral approval does not have effect, the scope of the appreciator's powers and responsibilities is clearly defined, and the phenomenon of unauthorized approval is prevented. Third, strictly control the inventory business process, standardize the management of enterprise inventory procurement, warehousing and other processes, so that everything is subject to the system, standardized, institutionalized management. Fourth, improve the inventory classification level, combine the $\mathrm{ABC}$ classification management method and the key factor analysis method, and also need to strengthen the inventory supervision [12].

\subsection{Strengthening Awareness of Inventory Management}

The lack of inventory management system and the confusion of inventory man- 
agement largely depend on the insufficient awareness of the importance of inventory management by the Reserve Grain Management Corporation. First, the corporate leadership should pay attention to enterprise inventory management. It is not only formal and superficial attention to inventory management, but the inventory management system should be truly implemented in the production and operation of enterprises. Inventory management indicators should be used as an important indicator of the assessment system, and the improvement and implementation of the inventory management system should be implemented. And manage inventory. The management of the company should lead by example. Only in this way can the enterprise form a good atmosphere that attaches importance to inventory management from top to bottom. Secondly, the ordinary employees of the enterprise should also establish a sense of paying attention to inventory management. Let the company's finance department, sales department, purchasing department, warehousing department and other relevant personnel truly implement the inventory management system, ensure the quality of execution, and realize the coordination degree and efficiency of each department through the sharing of inventory management information.

\subsection{Adopting Modern Inventory Management Mode}

The Reserve Grain Management Corporation still adopts the traditional inventory management model, and the management concept is no longer in line with the trend of the times. Due to the large number of inventory types of the enterprise, it is necessary to adopt a scientific and reasonable inventory management model to solve the inventory management problem, and combine the ABC inventory management law with the key factor management method [13]. The first step is to use $\mathrm{ABC}$ management method to classify the enterprise inventory, find out the key points in the large category, and generally determine the inventory classification according to the quantity and amount of the two classification methods. Because the amount of uncertainty is large and the classification is more responsible, so $\mathrm{ABC}$ classification is generally performed by quantity. In the second step, according to the principle of importance, after determining the category A inventory, the category B inventory, and the category $\mathrm{C}$ inventory, according to the key factor analysis method, the existence of the category $\mathrm{C}$ inventory cannot be ignored. Class $\mathrm{C}$ inventory is used as key inventory, and then Class $\mathrm{C}$ inventory is classified into high, medium and low levels according to the $\mathrm{ABC}$ management method. Through the above combination of $\mathrm{ABC}$ inventory management method and key factor analysis method, it constitutes the modern management mode of the enterprise.

\section{Conclusion}

Inventory management plays a vital role in the development of the company. It is the basis for ensuring product supply and adapting to market changes. Inventory management involves three parts of procurement, storage and shipment. 
Each link has taken appropriate measures to manage it, but it does not avoid some problems. Therefore, enterprises should find corresponding solutions to these problems. Then, in response to these problems, companies should find the corresponding solutions, start with the details, optimize each link, and realize the scientific management of the procurement, storage, and shipping process, and then provide protection for the enterprise.

\section{Conflicts of Interest}

The author declares no conflicts of interest regarding the publication of this paper.

\section{References}

[1] Wei, W. (2017) Research on Inventory Management of M Apparel Company. Guangxi University, Nanning.

[2] Huang, J. (2017) Research on Inventory Management Strategy of Small and Medium-Sized Pharmaceutical Circulation Enterprises. Guizhou University of Finance and Economics, Guiyang.

[3] Du, Y. (2017) Research on Inventory Management Model of SH Company. Hebei University of Economics and Business, Shijiazhuang.

[4] Shen, D. (2016) Basic Methods of Inventory Management and Basic Management of Operations. China Market, 5, 43-48.

[5] Liu, W. (2016) Current Situation and Countermeasures of Inventory Management of Agricultural Listed Companies-Taking Zhangzidao Company as an Example. Management Engineer, 3, 38-42.

[6] Ouyang, F. and Zeng, J. (2016) From the Perspective of Inventory Management, China's Market-Oriented Reform and State-Owned Enterprise Reform-An Empirical Study Based on Listed Companies in Manufacturing Industry. Economics and Management Review, 3, 61-72.

[7] Qin, L., Liao, W. and Tan, X. (2016) Problems and Countermeasures in Inventory Management of Publishing Enterprises. Journal of Southwest China Normal University (Natural Science), 4, 75-80.

[8] Tan, Q. and Wang, W. (2016) Inventory Management Problem of Small and Medium-Sized Enterprises. Chinese and Foreign Entrepreneurs, 3, 100-101.

[9] He, C. (2015) Inventory Management Problems and Countermeasures of Production Enterprises. Times Economy and Trade, 9, 12-15.

[10] Gao, F. (2015) Problems and Measures in Enterprise Inventory Management. Shopping Mall Modernization, 6, 29-31.

[11] Wang, J. (2017) Research on Internal Control of Inventory Management of $\mathrm{H}$ Company. Xi'an Petroleum University, Xi'an.

[12] Zhang, Y. (2017) Research on Inventory Risk Management of Y Reserve Grain Management Corporation. Xi'an Shiyou University, Xi'an.

[13] Zhou, B. (2017) Research on Working Capital Management of T Feed Company. Xiangtan University, Xiangtan. 